\title{
Factors Affecting Maternal Mortality at the Komfo Anokye Teaching Hospital Using the Audit Committee Report
}

\author{
Jane Acquaye', Boateng Nimako1, Robert Arkoh1, Eric Lartey Quarshie², Alex Osei Assim¹ \\ ${ }^{1}$ Department of Surgery, Komfo Anokye Teaching Hospital, Kumasi, Ghana \\ ${ }^{2}$ Obstetrics and Gynaecology Directorate, Komfo Anokye Teaching Hospital, Kumasi, Ghana \\ Email: maame.jenny@yahoo.com
}

How to cite this paper: Acquaye, J., Nimako, B., Arkoh, R., Quarshie, E.L. and Assim, A.O. (2021) Factors Affecting Maternal Mortality at the Komfo Anokye Teaching Hospital Using the Audit Committee Report. Open Access Library Journal, 8: e7678.

https://doi.org/10.4236/oalib.1107678

Received: June 22, 2021

Accepted: July 25, 2021

Published: July 28, 2021

Copyright $\odot 2021$ by author(s) and Open Access Library Inc.

This work is licensed under the Creative Commons Attribution International License (CC BY 4.0).

http://creativecommons.org/licenses/by/4.0/

(c) (i) Open Access

\begin{abstract}
Objective: The aim of the study aimed at identifying maternal mortality at the Komfo Anokye Teaching Hospital (KATH), using the audit committee report. Design: The study adopted a retrospective descriptive study by reviewing the folders of women who died in KATH using maternal mortality audit committee report. Settings: The study included all cases of maternal death audited by the KATH audit report committee between January and December 2017. Population: The study involved audited cases of maternal death at KATH. Main Outcome Measures: The main variables measured were demographics and characteristics of deceased women, the timing of onset of complications, place of death, antenatal clinic attendance, reported cause of death, service factors and individual factors identified by committees as having contributed to death, and recommendations made by audit committee. Results: 101 cases of maternal deaths were audited from January to December 2017. Out of these cases, deaths occurred mostly in the post-partum period. Fifty-three, representing $52.48 \%$ were due to direct causes, with post-partum hemorrhage as the leading cause $(49.06 \%)$, followed by sepsis $(28.3 \%)$ then amniotic fluid embolism (9.43\%). Indirect causes reported were cardiovascular disease, hepatitis B and, anemia with a percentage of $37.5 \%, 14.58 \%$ and, $6.25 \%$ respectively. Conclusions: Accessing maternal death using an audit approach will help the teams in the hospital to identify the direct and indirect causes of death, and their contributing factors, and to make recommendations for actions that would reduce the risk of reoccurrence. KATH can balance maternal death audits with other strategies to inform corrective measures.
\end{abstract}

\section{Subject Areas}

Gynecology \& Obstetrics 


\section{Keywords}

Maternal Death, KATH, Audit Committee Report

\section{Introduction}

Maternal death audit is a tool widely used and recommended to improve the quality of obstetric care and therefore reduction in maternal mortality. Maternal mortality, also known as obstetrical death, is the death of a woman while pregnant or within 42 days of termination of pregnancy, irrespective of the duration and site of the pregnancy, from any cause related to or aggravated by the pregnancy or its management but not from accidental or incidental causes.

Worldwide a woman dies every minute as a result of complications arising during pregnancy and childbirth and every year more than half a million women die due to complications of pregnancy and childbirth-99\% of these women live in developing countries.

Ghana like other developing countries has a high maternal mortality rate. The Ghana maternal health survey, 2016, indicates that the maternal mortality ratio in Ghana remains unacceptably high at 451 deaths per 100,000 live births.

Every minute, 380 women become pregnant; 190 women face unplanned or unwanted pregnancy; 110 women experience a pregnancy-related complication; 40 women have an unsafe abortion, and more than one woman dies of maternal causes. Improving the quality of Obstetric care is an urgent priority in developing countries, where maternal mortality remains high. The feasibility of criterion-based clinical audit of the assessment and management of five major obstetric complications is being studied in Jamaica and Ghana. Obstetric care of high quality continues to be a key requirement for reducing maternal mortality. However, the provision of effective, appropriate, accessible, and affordable obstetric care is difficult to define, measure, resource, sustain and evaluate. Nevertheless, approaches to a reduction in mortality such as clinical audit have proven to be an effective tool in improving the quality of obstetric care.

\section{Literature}

\subsection{Maternal Morbidity and Mortality}

According to the WHO, the major public concerns in some of the developing and resource-restrained countries are maternal morbidity and mortality (WHO, 2010) [1]. Approximations by the WHO show that about half a million, out of 8 million women who undergoes pregnancy related complications every year dies. Meanwhile, every pregnant woman hopes to give birth safely to a healthy baby, yet some normal pregnancies are accompanied by complications which are likely life threatening to both the mother and the fetus. Africa, Asia and other poor countries records the highest maternal mortality whereas about $1 \%$ of the deaths are recorded in the high income countries (WHO, 2010) [1]. 


\subsection{Causes of Maternal Death and Morbidity}

Events occurring from conception to 42 days postpartum are the causes of maternal deaths. Also, conditions arising, specifically from pregnancy in women's health within this period are known as direct obstetric conditions whiles those serious conditions caused by pregnancy in women's health are known as indirect obstetric conditions.

\subsection{Direct Obstetric Causes of Deaths}

Direct obstetric deaths are deaths of women as a result of pregnancy complications, from interventions, omissions, incorrect treatment, or a chain of events resulting from any of the above.

In most countries, especially in developing and developed countries, direct causes of maternal deaths change in quantifiable terms even though the quantitative measure appears the same. Maternal death Analysis in 2006 in Africa revealed that the leading causes of maternal deaths in Africa and Asia were hypertensive disorders, sepsis, hemorrhage, obstructed labor, infection, and abortion (Khan, Wojdyla, Say, Gülmezoglu \& Van Look, 2006) [2]. The result of the study showed that indirect causes of deaths causing maternal deaths were in the developing countries whiles the maternal deaths due to direct causes of death occur in the developed countries (Khan et al., 2006) [2]. The WHO estimates that South Asia and sub-Saharan record the majority of maternal deaths with the major causes of deaths be hypertension and hemorrhage.

However, the leading cause of death, that are related to complications of cesarean section and anesthesia, mostly occurs in the developed countries and reflects the world's differences and requires for obstetric care (WHO, 2016) [3].

Koblinsky et al. revealed that about $85 \%$ of maternal deaths occur from the direct obstetric cause of death in Bangladesh (NIH, 2018) [4], whiles direct causes of death like hemorrhage, sepsis/infection, and postpartum are the main causes of death in about $58 \%$ of the maternal deaths in Rajasthan, India (India, 2014) [5]. A study in Egypt shows that hypertensive disorders, postpartum, hemorrhage, a complication of cesarean section, and sepsis are the causes of death in about $85.7 \%$ of maternal. Estimations in Nigeria shows that in approximately $89.3 \%$ of maternal deaths, and the causes were sepsis, hemorrhage, post-abortion complications, obstructed labor, and eclampsia (PHP, 2015) [6].

It is found in Tanzania that the three leading direct causes of maternal deaths are hemorrhage, eclampsia, and sepsis (Bioline, 2010) [7] and this is no different from a study done in Ethiopia.

In identifying the commonest causes of direct causes of death, Negussie and Mesfin concluded that they are sepsis, obstructed labor, and abortion complications (Negussie \& Mesfin, 2009) [8]. According to Gaym, most of the causes of maternal deaths were due to unsafe abortion, sepsis, hemorrhage, ruptured uterus, eclampsia, and ectopic pregnancy in Ethiopia (Gaym, 2009) [9].

Following Hailu et al. study in Ethiopia., hemorrhage, sepsis, obstructed labor, and hypertensive disorders are the major causes of maternal death (Hailu, En- 
queselassie \& Berhane, 2009) [10].

\subsection{Indirect Obstetric Causes of Maternal Deaths}

Indirect obstetric causes of maternal deaths are existing diseases that were not due to obstetric causes but only develop during pregnancy and are serious effects of pregnancy (WHO, 2005) [11].

According to the WHO et al., one-fifth of all the maternal deaths in the world are as a results of indirect causes which includes HIV/AIDS, cardiac disorders, and malaria (WHO, 2005) [11].

In 2004, causes of maternal deaths as a result of indirect obstetric cause in developed countries were embolism. However, $4.6 \%$ of maternal deaths as a result of indirect causes were reported in Africa (WHO, 2005) [11]. Current estimates show that the world's maternal death as a result of indirect obstetric causes is $18 \%$ (WHO, 2010) [1].

In Pakistan, a study shows that indirect causes of deaths such as cardiac disorders, blood transfusion reactions are the causes of $12.8 \%$ maternal death (Filippi, Chou, Ronsmans, Graham \& Say, 2016) [12]. El-Gharib et al. also recorded $14.3 \%$ maternal deaths as a result of indirect causes of maternal deaths. A study in Nigeria indicated that out of $10.7 \%$ of maternal deaths resulting from indirect causes, anemia was responsible for 6\% (Mgawadere, Kana \& van den Broek, 2017) [13], whereas another research found that anemia was responsible for $6 \%$ out of $10.7 \%$ of maternal deaths from indirect obstetric causes.

Gaym, in Ethiopia, indicated that $5.1 \%$ of causes of maternal death that are not directly related to pregnancy were cardiac disease, infectious hepatitis, malaria, diabetes, intestinal obstruction and respiratory disorders (Gaym, 2009) [9]. One of the commonest indirect causes of death in Jimma, Ethiopia is cerebral malaria causing about 2.3\% of maternal death in 2009 (Negussie \& Mesfin, 2009) [8].

\subsection{Danger Signs of Obstetric Complications}

Danger signs during pregnancy are classified as severe weakness, tiredness, vomiting, nausea, high blood pressure, anemia, swelling of the face and hands, shortness of breath and bleeding from the vagina (Maymon et al., 2000) [14]. Moran et al. [15], showed that danger signs during labor and childbirth include premature rupture of membranes, severe bleeding after birth, abdominal pain, prolonged labor and sight disorders (NIH, 2010) [16]. Another study also state that danger signs during labor and childbirth are heavy bleeding, fever, water breaking but labor not starting within the hours of $8-12$, labor beginning before the eight month of pregnancy, cord prolapse, cord tightly wrapped around the baby's neck, baby breech, long contractions, convulsion and womb coming out together with the placenta (Creasy and Resnik, 2016) [17].

The most common danger signs after childbirth are monthly heavy bleeding, convulsion, fever, abdominal pain, unusual color discharge, reddened and swollen breast and hard and swollen legs (Moran et al., 2006) [15]. 


\subsubsection{Hemorrhagic Complication of Pregnancy}

Hemorrhage is placed the third among the causes of direct maternal death in advanced conception (Medline-UpToDate) [18].

\subsubsection{Bleeding from the Vagina}

There is the need for medical assessment in $5 \%-10 \%$ bleeding in late pregnancy (Lancaster, 2015) [19]. The third trimester or bleeding from the vagina has been ranked the cause of direct maternal death as a result of the seriousness and frequencies of obstetric hemorrhage and also the major cause of mortality and perinatal morbidity. Uterine rupture and placenta previa are the major causes of premature separation of the placenta. Bleeding during pregnancy which the causes can be placenta previa, abruption placentae and vasa previa is termed as antepartum hemorrhage (Obstetrics and gynaecology, 2016) [20], whiles this bleeding occurs in $3 \%$ to $5 \%$ of pregnancies above 22 weeks of gestation. Abruption placenta, placenta previa and vasa previa can cause the bleeding minimal or profuse (NIH, 2015) [21].

\subsubsection{Premature Separation of the Placenta}

Premature separation of the placenta is considered by tenderness and uterine pain and it is usually sudden at the beginning ("Obstetrics and gynaecology, 2016") [20]. The separation of the uterine implantation before delivery of the fetus is called the premature separation of the placenta, which mostly (Lancaster, 2015) [19]. It constitutes $30 \%$ of third trimester bleeding and about $80 \%$ of patients presenting with vaginal bleeding.

\subsubsection{Placenta Previa}

Placenta previa which is caused by sudden, painless and profuse hemorrhage occurs usually after 28 weeks of pregnancy. It occurs in 1 out of 200 births where about $90 \%$ of the patients are porous and the occurrence among grand multiparas be could be high as 1 in 20 ( Lancaster, 2015) [19].

\subsubsection{Uterus Rupture}

Another major cause of death is the rupture of pregnant uterus, it is likely obstetric disaster which usually occurs during labor and is considered as an increased supra pubic pain and tenderness accompanying with increased uterine touchiness and vaginal bleeding (Lancaster, 2015) [19].

\subsubsection{Premature Rupture of the Fetal Membrane}

Membrane rupture before the onset of labor is term as premature rupture of the fetal membrane or leaking of water from the vagina (Biggio et al., 2005) [22]. According to Roman and Pernoll, rupture of membrane can happen at any time during pregnancy and this becomes an issue when the fetus is preterm (McGrawHill, 2012) [23].

Research by Athayde et al. estimates that the frequency of the premature rupture of the fetal membrane is approximately $10 \%$ which is considered as very risky for maternal morbidity and mortality mostly occurring before 32 weeks 
(Biggio et al., 2005) [22]. According to Bennett, experiences preterm pre-labor rupture of membranes accounting for one third of all preterm deliveries and it is associated to pool of fluid in the vagina (Bennett, Rose, Myatt, \& Elder, 1987) [24]. Premature rupture of membrane can be also be termed as the break in bag of water and no signal of labor within 8 to 12 hours (Maymon et al., 2000) [14]. Also, premature rupture of the fetal membraneis caused by unexpected gush of fluid from the vagina with uterus reduced in size and increase status of fetus to palpation (McGraw-Hill, 2014) [25].

\subsubsection{Vaginal Bleeding in Labor}

Vaginal bleeding is one of the common causes of maternal death during labor, the bleeding is usually in a small amount and it is associated with cervical dilatation. During this period, patient experience profuse painless vaginal bleeding during and may signify that the earlier placenta previa which was not diagnosed complicates about $0.5 \%$ of pregnancies. Premature separation of placenta as a result of bloody fluid during the rupture of membranes is associated with uterine hypertonicity.

\subsubsection{Retained Placenta}

Retained placenta is irregular observance of the placenta to the uterine wall (Obstetrics and Gynaecology, 2016) [20].

\subsubsection{Hyperemesis Gravidarum}

Hyperemesis gravidarum is characterized by severe nausea and vomiting. This is usually experience among pregnant women when they develop intractable ketosis, weight loss, acetonuria and alteration of electrolyte imbalance (Obstetrics and Gynaecology, 2016) [20]. Hyperemesis gravidarumis associated with several pregnancies hydramnios, Giberman and hydatidiform mole. Hyperemesis gravidarum has been seen as persistent condition whiles vomiting in early pregnancies are usually associated with ketonuria weight loss and affects about few pregnant women (Goodwin, 2008) [26].

\subsubsection{Hypertensive Disorders of Pregnancy}

According to Abramovici et al., hypertension disorders, such as swollen hands, face and feet, blurred vision, loss of consciousness and severe headache are as a results of constant high blood pressure (Burris et al., 2014) [27]. Studies have also shown about $10 \%$ of all pregnancies experiences induced hypertension ("Obstetrics and gynaecology, 2016") [20], whiles hypertensive conditions of pregnancy can be chronic hypertension, preeclampsia, eclampsia or gestational hypertension (Burris et al., 2014) [27]. According to Miller, about 5\% - 7\% of all pregnancies are complicated by pre-eclampsia. Oedema of legs, hands and face can also be characterized by pre-eclampsia (Obstetrics and Gynaecology, 2016) [20]. Besides to these as the severity increases the sign of severe preeclampsia as visual disordersand irritability, headache and others. Furthermore, pre-eclampsia develops convulsion and or coma and other disorders not connected to cerebral conditions during pregnancies (Burris et al., 2014) [27]. 


\subsubsection{Postpartum Hemorrhage}

The uterine atony, which retains the placenta tissue, after delivery, causes more than $500 \mathrm{mls}$ loss of blood and occurs in about $5 \%$ of all pregnancies $(\mathrm{NIH}$, 2015) [28].

Postpartum hemorrhage is a deadly obstetric emergency (Obstetrics and Gynaecology, 2016) [20]. Postpartum bleeding can be major or minor. Early postpartum bleeding can occur with 24 hours after delivery, whiles the late postpartum bleeding occurs 24 hours after delivery (NIH, 2015) [28].

According to Elder, the secondary postpartum hemorrhage is an abnormal loss that occurs within 24hours after delivery (Obstetrics and Gynaecology, 2016) [20].

\subsubsection{Preterm Labor}

Preterm labor is a regular contradictions before pregnancy is 37 weeks completed (Obstetrics and Gynaecology, 2016) [20]. Preterm birth is also defined by Bennett delivery of a baby before completion of 37weeks (Bennett et al., 1987) [24].

\subsubsection{Infection}

Infections such as foul smelling of vaginal discharge, lower abdominal pain, high fever and awareness of heart beat during pregnancy are also causes of maternal mortality and morbidity.

The WHO defined infection as any bacterial infection of the genital tract occurring after delivery. Without prolonged rupture of membranes, signs and symptoms of infection occurs usually after 24 hors after delivery.

\subsubsection{Intrauterine Fetal Death}

Intrauterine fetal death/demise in other terms means no or reduced movement of the fetal.

This is the death of the unborn baby, and it occurs as a result of no reason, in a normal pregnancy. The incidence of this is about $1 \%$ of all pregnancies and it is mostly regarded as a fetal death occurring after 20 weeks of pregnancy with a fetal weight of less than or equal to 500 grams (Moon, Baek, Ahn \& Odibo, 2016) [29].

\subsubsection{Mal-Presentations}

Wrong lie of the baby or baby's hand or feet coming first is the Mal-presentations. Mal-presentation has been described as a breech presentation, crosswise lying with maybe the shoulder or arm presenting, it could also be face and brow presentation and cord presentation (Obstetrics and Gynaecology, 2016) [20].

Approximately $3 \%-4 \%$ of all pregnancies are being complicated by breech presentations. This is when the fetal pelvis occupies the maternal pelvic inlet (Adele, 2013) [30].

\subsubsection{Prolonged or Obstructed Labor}

Prolonged labor is a birth delay varies from between 12 hours and 24 hours (Obstetrics and gynaecology, 2016) [20].

\subsubsection{Anemia}

Lack of blood, shortness of breath and awareness of heartbeat is characterized by 
anemia. Anemia is an important maternal condition during pregnancy, usually as a result of nutritional deficiency in folic acid or iron. With reference to Centers for Disease Control, anemia is defined as "a hemoglobin concentration of less $11 \mathrm{~g} / \mathrm{dL}$ (hematocrit of $<33 \%$ ) in the first or third trimester or a hemoglobin concentration of less than $10.5 \mathrm{~g} / \mathrm{dL}$ (hematocrit $<32 \%$ ) in the second trimester". According to Elder, nutritional iron deficiency anemia is the most common hematological problem. Nutritional iron deficiency anemia is found in between $20 \%$ and $30 \%$ of pregnancies, and it is usually among women with poor nutrition and the resource restrained (Obstetrics and Gynaecology, 2016) [20].

\subsubsection{Umbilical Cord Prolapse}

Kis and Collea defines cord prolapse, which also means cord coming before the baby as the lineage of the umbilical cord into the lower uterine segment (44). Prolapse of the umbilical cord to an extent shows the cord to intermittent compression at the pelvic inlet, cervix or vaginal canal. This can be observed simply by picturing the cord swelling from the vaginal canal.

\subsubsection{Amniotic Fluid Embolus}

Amniotic fluid, also loss of consciousness or shortness of breath occurs when the fluid discharges from the sac into the uterine veins and causes a pulmonary movement through anaphylactic reaction and can result in dyspnea, collapse, shock and DIC (37).

\subsubsection{Uterine Inversion}

Uterine inversion is when the womb is coming out. It is an occasional condition where the fundus comes down through the cervix (Obstetrics and Gynaecology, 2016) [20].

\section{Methodology}

\subsection{Study Design}

The study design is a retrospective study, reviewing the folders of women who died in KATH from January to December, 2017 using maternal mortality audit report.

\subsection{Population}

Population is mothers whose deaths were audited.

\subsection{Data Type and Scope}

The data for this study focused on concept, procedures processes and constitution of audit committees and methods to addressing the identified issue. However, data collected were limited to information provided by the audit committee.

\subsection{Sources of Data and Methods of Data Collection}

The main source of data used was primary source of data. Data were retrieved 
from the records of the audit committee.

\subsection{Methods of Data Analysis and Reporting Framework}

Data were collated, synthesized and analyzed using both qualitative and quantitative analytical techniques. Tables, percentages, cross tabulation and graphs were used to present the quantitative aspect of the study. Descriptive analysis was used to explain the qualitative part of the research. The findings and recommendations of the analysis were deduced from the discussions.

\section{Results}

\subsection{Socio-Demographic Characteristics of Deceased Women}

One hundred and one deaths were recorded under the year of review. Out of the 101 deceased women, 59 (58.42\%) of the women died at the age of 28 - 37 years with an mean and standard deviation of 30.22 and 6.31 years respectively. The ages range from 17 years to 46 years. More than half 70 (69.31\%) reside in the urban community's with $70(69.31 \%)$ had completed basic education and 15 (14.85\%) had no formal education. Two third 67 (66.34\%) were married and equal proportion $17(16.83 \%)$ of the women were single and living together respectively. More than one-third 36 (35.64\%) were trading and 6 (5.94\%) were civil/public servant. More than three-quarters 84 (83.17\%) were Christians. More than two-thirds 69 (68.32\%) of the women belonged to the Akan ethnicity and 7 (6.93\%) were Ewe's (Table 1).

\subsection{Obstetric Information of the Deceased Pregnant Women}

Out of the 101 deceased women, more than three quarters $80(79.21 \%)$ of the women assessed ANC during pregnancy. Out of this, majority $57(71.25 \%)$ of the women visited the ANC more than 4 times. More than one third 33 (41.25\%) of the women reported visiting health center/clinic ANC. The average gestational age of ANC booking was 14.24 weeks with a standard deviation of 6.85 weeks. Previous $\mathrm{C} / \mathrm{S}$ and sickle cell disease (SCD) was emerged as the risk factors observed during ANC visits with a percentage of $10.00 \%$ and $11.25 \%$ respectively. HIV status was observed in 11 (13.75\%) of the deceased women (Table 2).

\subsection{Labor and Delivery Characteristics of the Deceased Women}

The study revealed that, labor occurred in more than half $66(65.35 \%)$ of the women before seeking health care. There was an induced labor in almost onethird 30 (29.70\%) of the women. Labor augmentation was done for only 9 (8.91\%) of the women. Partograph was used $22(21.78 \%)$ to monitor the wellbeing of the mother and fetus, 64 (63.37\%) of the women delivered successfully. Out of those who delivered, more than one-third 25 (39.06\%) delivered at the teaching hospital, 36 (56.25\%) were delivered by midwives. A little over half 33 (51.56\%) delivered through SVD. More than half 40 (62.50\%) had a live birth and 2 (3.13\%) had macerated stillbirth. Almost three-quarters 72 (71.29\%) died at the teaching 
Table 1. Socio-demographic characteristics of deceased women.

\begin{tabular}{|c|c|c|}
\hline Variable & Frequency $(n=101)$ & Percentage (\%) \\
\hline \multicolumn{3}{|l|}{ Age (years) } \\
\hline$-\leq 28$ & 28 & \\
\hline$-28-37$ & 59 & 27.72 \\
\hline$->37$ & 14 & 58.42 \\
\hline Mean (SD) & $30.22( \pm 6.31)$ & 13.86 \\
\hline \multicolumn{3}{|l|}{ Residency } \\
\hline - Rural & 31 & 30.69 \\
\hline - Urban & 70 & 69.31 \\
\hline \multicolumn{3}{|l|}{ Educational levels } \\
\hline - None & 15 & 14.85 \\
\hline - Basic education & 70 & 69.31 \\
\hline - Secondary education & 12 & 11.88 \\
\hline - Tertiary education & 4 & 3.96 \\
\hline \multicolumn{3}{|l|}{ Marital status } \\
\hline - Single & 17 & 16.83 \\
\hline - Living together & 17 & 16.83 \\
\hline - Married & 67 & 66.34 \\
\hline \multicolumn{3}{|l|}{ Occupation } \\
\hline - Unemployed & 23 & 22.77 \\
\hline - Trading & 36 & 35.64 \\
\hline - Fishing/farming & 10 & 9.90 \\
\hline - Artisan & 26 & 25.74 \\
\hline - Civil/public servant & 6 & 5.94 \\
\hline \multicolumn{3}{|l|}{ Religion } \\
\hline - Christianity & 84 & 83.17 \\
\hline - Muslim & 17 & 16.83 \\
\hline \multicolumn{3}{|l|}{ Ethnicity } \\
\hline - Akan & 69 & 68.32 \\
\hline - Mole dagbani & 10 & 9.90 \\
\hline - Ga adangbe & 8 & 7.92 \\
\hline - Ewe & 7 & 6.93 \\
\hline - Other & 7 & 6.93 \\
\hline
\end{tabular}

Table 2. Obstetric information of the deceased pregnant women.

\begin{tabular}{lcc}
\hline \multicolumn{1}{c}{ Variable } & Frequency $(\mathbf{n}=101)$ & Percentage (\%) \\
\hline ANC during pregnancy & & \\
- No & 21 & 20.79 \\
- Yes & 80 & 79.21 \\
Number of times of ANC visit (times) & $\mathbf{n}=80$ & \\
- $\leq 4$ & 23 & 28.75 \\
- >4 & 57 & 71.25 \\
Mean (SD) & $5.81( \pm 2.63)$ & \\
Place of ANC & $\mathrm{n}=80$ & 7.50 \\
- Teaching hospital & 6 & 6.25 \\
- Regional hospital & 5 & 35.00 \\
- District hospital & 28 & 41.25 \\
- Health centre/clinic & 33 & 7.50 \\
- Private maternity home & 6 & 2.50 \\
- Other & 2 & \\
\hline
\end{tabular}




\section{Continued}

\begin{tabular}{lcc}
\hline Gestational age at booking (weeks) & $\mathbf{n}=\mathbf{8 0}$ & \\
$\quad-\leq 12$ & 37 & 46.25 \\
-12 & 43 & 53.73 \\
Mean (SD) & $14.24( \pm 6.85)$ & \\
ANC risk factors & $\mathbf{n}=\mathbf{8 0}$ & 57.50 \\
- None & 46 & 2.50 \\
- Previous PPH & 2 & 3.75 \\
- Hepatitis B & 3 & 5.00 \\
- HPT & 4 & 10.00 \\
- Previous C/S & 8 & 11.25 \\
- SCD & 9 & 10.00 \\
- Other & 8 & \\
HIV status & $\mathbf{n}=\mathbf{8 0}$ & 71.25 \\
- Non - reactive & 57 & 13.75 \\
- Reactive & 11 & 15.00 \\
- Not indicated & 12 &
\end{tabular}

hospitals and more than one quarter $36(35.64 \%)$ spent $>24$ hours on admission before death (Table 3 ).

\subsection{Direct Causes of Death}

In regards to causes of death, a little over half 53 (52.48\%) of the causes of death were direct causes. The three leading direct causes of death were haemorrhage, sepsis and amniotic fluid embolism with a percentage of $49.06 \%, 28.30 \%$ and 9.43\% respectively (Figure 1 ).

\subsection{Indirect Causes of Death}

The 3 topmost leading cause of death were cardiovascular disease, hepatitis B and anaemia with a percentage of $37.5 \%, 14.58 \%$ and $6.25 \%$ respectively (Figure 2).

\subsection{Contributory Factors to Death}

The contributory factors that led to the death of the women were personal/family/community factors and health personnel related problems with a percentage of $40.85 \%$ and $30.99 \%$ respectively (Figure 3 ).

\subsection{Factors Affecting Maternal Mortality}

The study revealed a significant association between the predictor variable (residential status, ANC visit, and time from admission to death) and the outcome variable (direct causes of death). Based on the results, urban residency were 7.49 times more likely to die from direct causes of death as compared to women who reside in the rural community's $(\mathrm{aOR}=7.49, \mathrm{CI}=2.15-26.11, \mathrm{p}=0.002)$. Women who did not assess ANC during pregnancy were 10.66 times more likely to die from direct causes of death as compared to pregnant woman who sought ANC during pregnancy $(\mathrm{aOR}=10.66, \mathrm{CI}=1.92-59.19, \mathrm{p}=0.006)$. Also, women 
Table 3. Labor and delivery characteristics of the deceased women.

\begin{tabular}{lcr}
\hline Variable & Frequency $(\mathbf{n}=\mathbf{1 0 1})$ & Percenta \\
\hline Labor occurred & & \\
- No & 33 & 32.6 \\
- Yes & 66 & 65.35 \\
- Not indicated & 2 & 1.98
\end{tabular}

Labor induced

$\begin{array}{lll}\text { - No } & 49 & 48.51 \\ \text { - Yes } & 30 & 29.70 \\ \text { - Not indicated } & 22 & 21.78\end{array}$

Labor augmented

- No

- Yes

- Not indicated

Partograph used

$\begin{array}{lll}\text { - No } & 47 & 46.53 \\ \text { - Yes } & 22 & 21.78 \\ \text { - Not indicated } & 32 & 31.68\end{array}$

\section{Patient delivered}

- No

- Yes

- Not indicated

Place of delivery

- Health centre/clinic

- Home

$\mathrm{n}=64$

- District hospital

- Teaching hospital

26.56

- Not indicated

Delivered by

- Midwife

- Doctor

Mode of delivery

- C/S

- SVD

Delivery outcome

- Macerated stillbirth

- Fresh stillbirth

- Live birth

Place of death

$$
\begin{aligned}
& \text { - Regional hospital } \\
& \text { - Teaching hospital } \\
& \text { - Not indicated }
\end{aligned}
$$

Time interval between admission and death (hrs)

$\begin{array}{lcc}-<6 & 18 & 17.82 \\ -\quad 6-12 & 8 & 7.92 \\ -13-24 & 22 & 21.78 \\ ->24 & 36 & 35.64\end{array}$




\section{0}

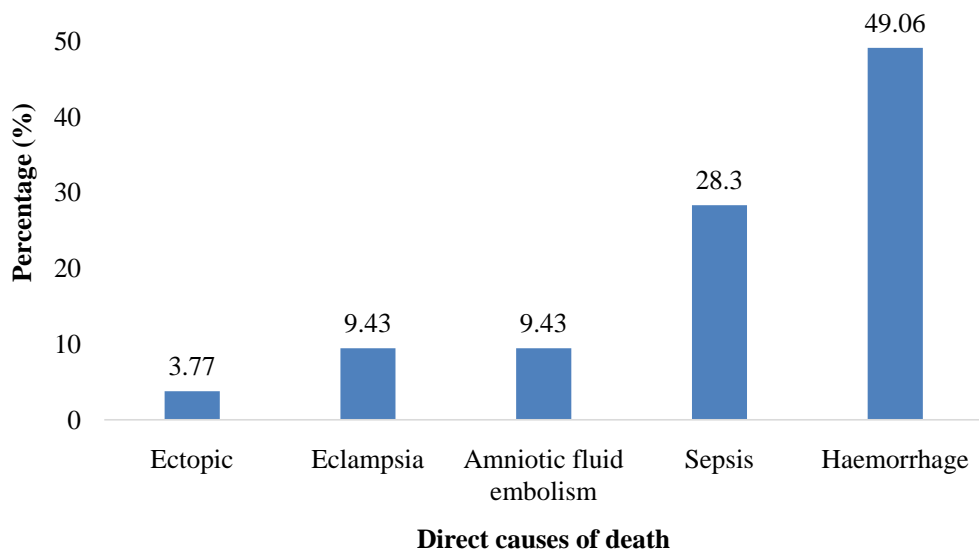

Figure 1. Distribution of direct causes of death.

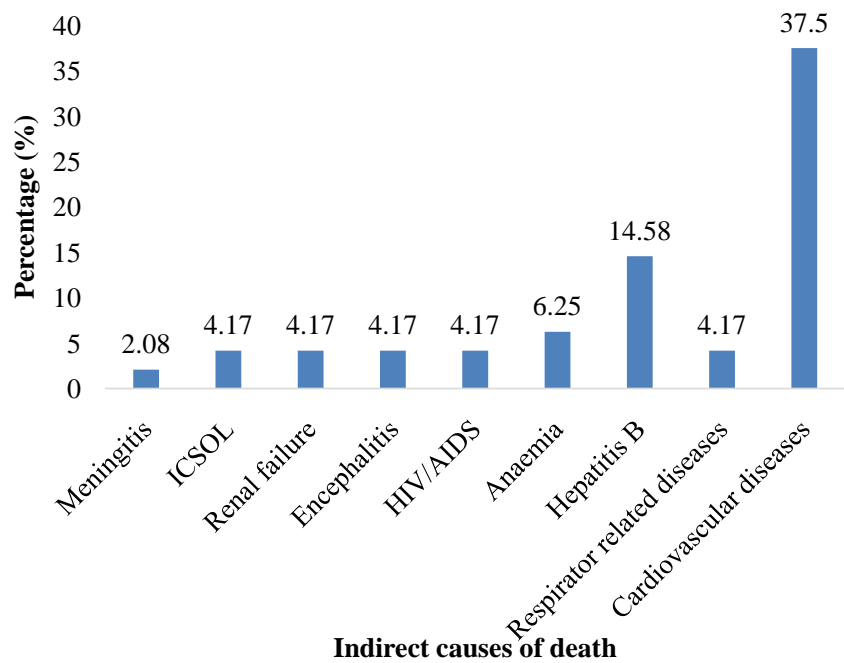

Figure 2. Distribution of indirect causes of death.

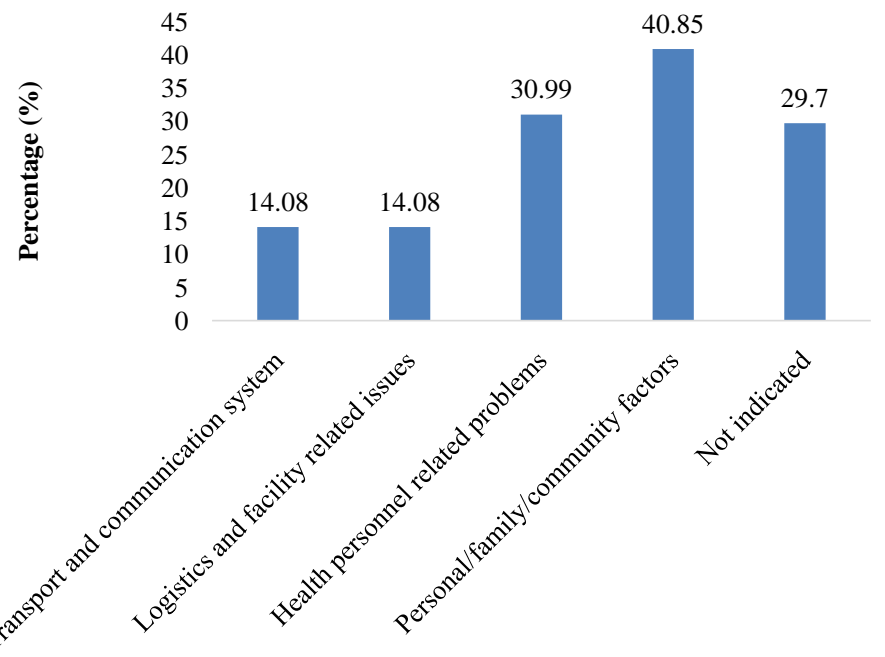

Contributory causes of death

Figure 3. Distribution of contributory factors of death. 
Table 4. Bivariate and multivariate analysis of factors affecting maternal mortality.

\begin{tabular}{|c|c|c|c|c|}
\hline Variable & OR $(95 \% \mathrm{CI})$ & p-value & aOR $(95 \% \mathrm{CI})$ & p-value \\
\hline \multicolumn{5}{|l|}{ Age (years) } \\
\hline$-\leq 27$ & 1.00 & & 1.00 & \\
\hline$-28-37$ & $0.55(0.22-1.36)$ & 0.195 & $0.30(0.08-1.13)$ & 0.075 \\
\hline$->37$ & $1.16(0.31-4.41)$ & 0.822 & $1.15(0.14-9.55)$ & 0.897 \\
\hline \multicolumn{5}{|l|}{ Residency } \\
\hline - Rural & 1.00 & & 1.00 & \\
\hline - Urban & $6.57(2.48-17.44)$ & $<0.000^{*}$ & $7.49(2.15-26.11)$ & $0.002^{*}$ \\
\hline \multicolumn{5}{|l|}{ Occupation } \\
\hline - Unemployed & 1.00 & & 1.00 & \\
\hline - Trading & $0.28(0.06-1.35)$ & 0.112 & $0.23(0.02-2.41)$ & 0.218 \\
\hline - Fishing/farming & $0.72(0.25-2.08)$ & 0.542 & $0.56(0.14-2.23)$ & 0.409 \\
\hline - Artisan & $0.88(0.28-2.75)$ & 0.821 & $0.77(0.15-3.85)$ & 0.748 \\
\hline - Civil/public servant & $0.32(0.05-2.13)$ & 0.240 & $0.09(0.01-1.10)$ & 0.059 \\
\hline \multicolumn{5}{|l|}{ ANC visit } \\
\hline - Yes & 1.00 & & 1.00 & \\
\hline - No & $2.76(0.97-7.84)$ & 0.056 & $10.66(1.92-59.19)$ & $0.007^{\star}$ \\
\hline \multicolumn{5}{|l|}{$\begin{array}{l}\text { Time from admission to } \\
\text { death (hrs) }\end{array}$} \\
\hline$-<6$ & 1.00 & & 1.00 & \\
\hline$-6-12$ & $0.48(0.08-2.92)$ & 0.422 & $0.54(0.06-4.90)$ & 0.582 \\
\hline$-13-24$ & $0.29(0.07-1.15)$ & 0.077 & $0.33(0.06-1.77)$ & 0.198 \\
\hline$->24$ & $0.16(0.04-0.59)$ & $0.006^{*}$ & $0.11(0.02-0.56)$ & $0.007^{*}$ \\
\hline - Not indicated & $0.41(0.09-1.78)$ & 0.233 & $0.36(0.06-2.13)$ & 0.260 \\
\hline
\end{tabular}

who spent more than 24 hours from admission before death were $89.00 \%$ less likely to die from direct causes of death as compared to their other counterparts $(\mathrm{aOR}=0.11, \mathrm{CI}=0.02-0.56, \mathrm{p}=0.007)($ Table 4$)$.

\section{Conclusion and Recommendation}

\subsection{Conclusion}

Accessing maternal death using an audit approach will help the teams in the hospital to identify the direct and indirect causes of death, and also, contribute to factors in making recommendations for actions that would reduce the risk of recurrence. KATH can balance maternal death audits with other strategies to inform corrective measures.

\subsection{Recommendation}

Management of Obstetric Complications

- Strengthening of postoperative follow-up

- Close monitoring after anaesthesia injection

- Strengthening of post-partum follow-up

- Strengthening the use of partograph

- Strengthening the hygienic measures in the post-operative period

- Strengthening follow-up for patient admitted for obstetrical pathology
Availability of Medicines and Infrastructure

- Ensure the availability of blood, especially Rhesus negative

- Avail emergency kits, laboratory test

- Avail resuscitation materials and anaesthesia equipment

- Avail intravenous antihypertensive treatment

- Refer patient in a critical condition to the ICU 


\section{Continued}

- Strengthening the quality of ANC

- Adhering to protocols

- Close follow-up in case of blood transfusion

- Reinforce HIV patient follow-up by including home visit

- Reinforce preoperative preparation

\section{Communication}

- Strengthen communication among staff as well as departments within the hospital

- Strengthen communication between health facilities

- Strengthen communication between health providers and patients

\section{Referral System}

- Refer patient with complications on time to a higher level

- Provide adequate pre-transfer treatment

- Avail more ambulances

\section{Human Resources}

- Training on emergency obstetric and neonatal care, especially on surgery

- Increase number of health providers

- Hire an anesthesia technician

- Training on resuscitation procedures

\section{Conflicts of Interest}

The authors declare no conflicts of interest.

\section{References}

[1] World Health Organization (WHO) (2010) Trends in Maternal Mortality: 1990 to 2010. World Health Organization, Geneva.

[2] Khan, K.S., Wojdyla, D., Say, L., Gülmezoglu, A.M. and Van Look, P.F. (2006) WHO Analysis of Causes of Maternal Death: A Systematic Review. Lancet, 367, 1066-1074. https://doi.org/10.1016/S0140-6736(06)68397-9

[3] World Health Organization (WHO) (2016) Maternal Mortality Ratio. World Health Organization, Geneva.

[4] Koblinsky, M., Anwar, I., Mridha, M.K., Chowdhury, M.E. and Botlero, R. (2018) Reducing Maternal Mortality and Improving Maternal Health: Bangladesh and MDG 5. Journal of Health, Population and Nutrition, 26, 280-294. https://doi.org/10.3329/jhpn.v26i3.1896

[5] Iyengar, K., Iyengar, S.D., Suhalka, V. and Dashora, K. (2009) Pregnancy-Related Deaths in Rural Rajasthan, India: Exploring Causes, Context, and Care-Seeking through Verbal Autopsy. Journal of Health, Population and Nutrition, 27, 293-302. https://doi.org/10.3329/jhpn.v27i2.3370

[6] Olopade, F.E. and Lawoyin, T.O. (2015) Maternal Mortality in a Nigerian Maternity Hospital. African Journal of Biomedical Research, 11, 267-273. https://doi.org/10.4314/ajbr.v11i3.50726

[7] Bioline (2010) International Official Site (Site Up-Dated Regularly). http://www.bioline.org.br/

[8] Negussie, D. and Mesfin, N. (2009) Review of Maternal Death in Jimma University Specialized Hospital. Ethiopian Journal of Health Sciences, 19, 9-12. https://www.ajol.info/index.php/ejhs/article/view/145936

[9] Gaym, A. (2009) Maternal Mortality Studies in Ethiopia-Magnitude, Causes and Trends. Ethiopian Medical Journal, 47, 95-108.

[10] Hailu, S., Enqueselassie, F. and Berhane, Y. (2009). Health Facility-Based Maternal Death Audit in Tigray, Ethiopia. Ethiopian Journal of Health Development, 23, 115-119. https://doi.org/10.4314/ejhd.v23i2.53226

[11] World Health Organization (WHO) (2005) Maternal Mortality in 2005. World Health 
Organization, Geneva.

[12] Filippi, V., Chou, D., Ronsmans, C., Graham, W. and Say, L. (2016). Levels and Causes of Maternal Mortality and Morbidity. In: Black, R.E., Laxminarayan, R., Temmerman, M. and Walker, N., Eds., Disease Control Priorities, 3rd Edition, Vol. 2, World Bank, Washington DC, 51-70. https://doi.org/10.1596/978-1-4648-0348-2_ch3

[13] Mgawadere, F., Kana, T. and van den Broek, N. (2017) Measuring Maternal Mortality: A Systematic Review of Methods Used to Obtain Estimates of the Maternal Mortality Ratio (MMR) in Low- and Middle-Income Countries. British Medical Bulletin, 121, 121-134. https://doi.org/10.1093/bmb/ldw056

[14] Maymon, E., Romero, R., Pacora, P., Gomez, R., Athayde, N., Edwin, S., \& Yoon, B. H. (2000) Human Neutrophil Collagenase (Matrix Metalloproteinase 8) in Parturition, Premature Rupture of the Membranes, and Intrauterine Infection. American Journal of Obstetrics and Gynecology, 183, 94-99. https://doi.org/10.1016/S0002-9378(00)99072-0

[15] Moran, A.C., Sangli, G., Dineen, R., Rawlins, B., Yaméogo, M. and Baya, B. (2006) Birth-Preparedness for Maternal Health: Findings from Koupéla District, Burkina Faso. Journal of Health, Population, and Nutrition, 24, 489-497.

[16] Moran, A.C., Sangli, G., Dineen, R., Rawlins, B., Yaméogo, M. and Baya, B. (2010) Birth-Preparedness for Maternal Health: Findings from Koupéla District, Burkina Faso. Journal of Health, Population and Nutrition, 24, 489-497

[17] Bennett, P.R., Rose, M.P., Myatt, L. and Elder, M.G. (1987) Preterm Labor: Stimulation of Arachidonic Acid Metabolism in Human Amnion Cells by Bacterial Products. American Journal of Obstetrics and Gynecology, 156, 649-655. https://doi.org/10.1016/0002-9378(87)90070-6

[18] Resnik, R., Creasy, R.K., Iams, J.D., Lockwood, C.J., Moore, T. and Greene, M.F. (2009) Creasy and Resnik's Maternal-Fetal Medicine: Principles and Practice. Saunders Elsevier, Philadelphia.

[19] Lockwood, C. J. (2011) Overview of Postpartum Hemorrhage. https://sompomed.org

[20] Lancaster (2015) Placenta Abruptio-Topic Overview.

[21] Elder, M.G. (2002) Obstetrics and Gynaecology : Clinical and Basic Science Aspects. Imperial College Press, London. https://trove.nla.gov.au/version/39129049

[22] Gyimah, S.O., Takyi, B.K. and Addai, I. (2015) Challenges to the Reproductive-Health Needs of African Women: On Religion and Maternal Health Utilization in Ghana. Social Science \& Medicine, 62, 2930-2944. https://doi.org/10.1016/j.socscimed.2005.11.034

[23] Biggio, J.R., Ramsey, P.S., Cliver, S.P., Lyon, M.D., Goldenberg, R.L. and Wenstrom, K.D. (2005) Midtrimester Amniotic Fluid Matrix Metalloproteinase-8 (MMP-8) Levels above the 90th Percentile Are a Marker for Subsequent Preterm Premature Rupture of Membranes. American Journal of Obstetrics and Gynecology, 192, 109 113. https://doi.org/10.1016/j.ajog.2004.06.103

[24] DeCherney, A., Lauren, N., Murphy, G.T. and Neri, L. (2012) Chapter 14. Late Pregnancy Complications. In: McGraw-Hill, Ed., Current Diagnosis \& Treatment: $\mathrm{Ob}$ stetrics \& Gynecology, 11th Edition, McGraw-Hill Medical, New York, 1088 p.

[25] DeCherney, A., Lauren, N., Murphy, G.T. and Neri, L. (2014) Chapter 34. Hematologic Disorders in Pregnancy In: McGraw-Hill, Ed., Current Diagnosis \& Treatment: Obstetrics \& Gynecology, 11th Edition, McGraw-Hill Medical, New York, $1088 \mathrm{p}$. 
[26] Murphy Goodwin, T. (2008). Hyperemesis Gravidarum. Obstetrics and Gynecology Clinics of North America, 35, 401-417. https://doi.org/10.1016/j.ogc.2008.04.002

[27] Burris, H.H., Rifas-Shiman, S.L., Huh, S.Y., Kleinman, K., Litonjua, A.A., Oken, E., et al. (2014) Vitamin D Status and Hypertensive Disorders in Pregnancy. Annals of Epidemiology, 24, 399-403.e1. https://doi.org/10.1016/j.annepidem.2014.02.001

[28] Butwick, A.J., Ramachandran, B., Hegde, P., Riley, E.T., El-Sayed, Y.Y. and Nelson, L.M. (2015) Risk Factors for Severe Postpartum Hemorrhage after Cesarean Delivery: Case-Control Studies. Anesthesia \& Analgesia, 125, 523-532. https://doi.org/10.1213/ane.0000000000001962

[29] Moon, M., Baek, M.J., Ahn, E. and Odibo, A.O. (2016) Association between Small for Gestational Age and Intrauterine Fetal Death: Comparing a Customized South Korean Growth Standard versus a Population-Based Fetal Growth Chart. The Journal of Maternal-Fetal \& Neonatal Medicine, 29, 872-874.

https://doi.org/10.3109/14767058.2015.1027189

[30] Pillitteri, A. (2013) Maternal \& Child Health Nursing: Care of the Childbearing \& Childrearing Family. Lippincott Williams \& Wilkins, Philadelphia. 